\title{
TOT LOF VAN DIE KERKORDE ... IN SY DIENSKNEGGEWAAD (1)
}

C. J. Smit

\section{VOORAF}

Dit is eg Gereformeerd om te sê dat die kerkorde nie 'n wetboek is nie. En ons is heel dikwels eg Gereformeerd! Maar hoe dan met die kerkorde gemaak? Jou oë vir hom sluit, hom tong in die kies vernuftig probeer systap; of tog dan maar ' $n$ wet van hom gaan staan en maak? Moet ons hom maar aanvaar as die erflike las waarmee die kerk sit en wat nou eenmaal saamgesleep móét word? Moet ons hom maar in ons midde duld as die arsenaal waaruit die grootkanonne hulle kartetse haal om met baie donder en min erbarming hulle (vermoedelike) teëstanders op kerklike vergaderings mee plat te skiet?

Hoe moet ons die kerkorde sien? Dit is my erns om u die kerkorde met waardering op sy regte plek te laat sien... in 'n dienskneggewaad.

\section{KERKORDE IN DIENS VAN... DIE VREDE}

Laat ons by die hart van die saak begin, by die eerste woorde wat in die Dordtse kerkorde geskryf staan. Maar laat ons dit doen gedagtig aan die historiese agtergrond van veral luister en herluister na die Woord van God, met die daaropvolgende wik en skik, oorweeg en oorreed, redeneer en formuleer deur die loop van baie sinodes (vgl. Hooijer 1865; Rutgers 1890 en 1980; Pont 1981; ibid 1978: 29), waardeur die orde in die kerk uiteindelik skón gefiltreer het:

"Om goede ordre in der Gemeente Christi te onderhouden, zijn daar in nodig de Diensten, te Zamenkomsten, opzicht der Leere, Sacramenten en Ceremonien, en Christelijke straffe. Waar van hier na ordentelijk zal gehandelt worden" (Dordtse kerkorde, art. 1 in Hooijer 1865 : 449).

Toegegee, dit lyk asof die orde, en daarby nogal keurig bepaal "die goeie orde", die verklaarde einddoel van die kerkorde is. En 'n mens sou wou vra: het ons, soos wat die verabsolutering van 'n idee die tirannie van 'n ideologie ten gevolg het, hier met orde as 'n abstrakte grootheid, 'n "ordologie", te doen? 'n Vraag wat sekerlik gestel sou word, ten minste as die kerkorde buite-om sy historiese én sy skrifbepaalde doel besien word.

Reeds in die ontwerp-kerkorde van die kerklike samekoms te Wezel op 3 November 1568 is die kerkorde in die inleidingspassasie daarvan by wyse van 'n kanttekening met 1 Korintiërs 14:40 gemotiveer (Rutgers 1980:9): "Laat alles betaamlik en ordelik gebeur".

Struktureel gesien lê hierdie teks se wortels in 'n paar verse boontoe: "God is tog nie 'n God van wanorde (akatastasias) nie, maar van vrede (eirenés) (1 Kor. 14:33). Op die oog af word hier 'n vreemde, moontlik slordige teenstelling gemaak: wanorde teenoor vrede. In ons netjies gekategoriseerde denkwyse sou ons ten minste 
die geykte 'orde' as die vanselfsprekende teenoorgestelde van 'wanorde' verwag het. Maar Paulus is geen slordige taalhanteerder nie: die teëstellinge wat die Skrif maak, lê meermale buite die reikwydte van ons vanselfsprekende verwagtinge. (En tog het die vertalers van die nuwe Afrikaanse Bybelvertaling - by die pragtige winspunte in die nuwe vertaling! - hier "op die oog af" vertaal. Hulle vind dit nodig om die teenstelling wat Paulus hier maak tot sy "netjiese, logiese vanselfsprekendheid" deur te trek, daarom parafraseer hulle: "God is tog nie 'n God van wanorde nie, maar van orde en vrede" (My kursivering: C. J. S.). Daardie 'orde' (taksis) wat die vertalers hier, klaarblyklik ter wille van die logiese afronding van Paulus se teenstelling insluip, kon ek in geen verwysing na die ou manuskripte vind nie).

Die apostel Paulus se "onlogiese" teenstelling tussen wanorde en vrede het 'n definitiewe betekenis. Gesien uit die perikoop van vers 26 tot vers 40 , met vers 40 as die samevattende sluitsteen, word die horisontaal-negatiewe lyn van orde na wanorde verlê na 'n vertikaal-positiewe lyn van orde na vrede toe. Dit beteken dat die orde in die vrede gewortel is, en nader bepaal: in die vrede van God (vgl. Kamphuis $1966: 14$ ). Hier, meen ek, kom ons by die bestaansgrond van die kerkorde: die urede van God wat ons by die God van vrede bring. Dit is onmoontlik dat die kerk selfs kan begin om God te dien as dit buite om die vrede gedoen word (vgl. Calvyn oor 1 Kor. $14: 401972: 244$ ).

Omđat God vrede wil, dáárom skep Hy orde (vgl. Grosheide oor 1 Kor. 14:40 1957: 378). Vanweë die vrede móét daar dus orde wees: orde is ' $n$ vrug van die vrede met God. Om gestalte aan dié orde te gee, moet daar in die eerste plek dienste wees wat die vrede van die evangelie kan bedien. Daarom begin die kerkorde nie by die leer van die kerk, of by die vergadering van die kerk nie, maar by die dienste, die verkondiging van die Woord. Hierin word die kerk as verloste volk van God, en derhalwe die nuwe mensheid, gekonstitueer. In hierdie sobere aanvangsreëls van die kerkorde hoor u die hartslag van ons onderwerp!

Die punt wat ek stel is: die orde is gesubordineer aan die vrede. En die vrede van God, die Nuwe Testamentiese vrede (eirênés), het vanselfsprekend alles met Christus te make. Sonder Hom kan daar geen vrede met God wees nie. Die vrede in Christus dui op 'n totale lewensherstel (Lk. 2:14) as gevolg van die herstelde verhouding met God (Rm 5:1) (vgl. Ridderbos $1960: 219$ ). Vrede is dus nie allesbeheersende gevolg van die versoeningsdaad in en deur Jesus Christus (vgl. ibid 1971: 198). En die versoening is nie slegs 'n aanmaning om die vyandige gesindheid teenoor God te laat vaar nie. Nee, dit is 'n radikale, allesveranderende daad van Christus waardeur Hy die mens letterlik teen wil en dank weer die plek laat inneem waarop hy deur God "neergesit" is (vgl. Pop 1978 : 337). Vrede, as dié gevolg van die versoening, is voluit eskatologies bepaald (vgl. Vine s.j. : 851): dit is 'n aanduiding van die allesomvattende eskatologiese heilsgawe: die komende toestand (en verhoudinge) van sjaloom waarna 
die Ou Testament hunker (vgl. Ps. $29: 11 ; 35: 27 ; 37: 11,37,72: 7$; $85: 11 ; 119: 165)$ waarin God weer die onbeperk-erkende heerskappy sal hê (vgl. Ridderbos $1955: 249$ ).

1 Korintiërs $14: 33$ het ook die betekenis dat waar die sonde heers, is daar wanorde, maar waar God heers, is daar vrede. Binne die kader van vrede met God en met mekaar, as 'n vrug van die heil in en deur Jesus Christus, skenk Christus orde as 'n gawe aan sy kerk (vgl. Vine s.j. : 851 V). Anders gestel: omdat Hyself die vrede van sy kerk is (Ef $2: 14 \mathrm{vv}$ ), kom die orde van die kerk van Homself (vgl. Van der Walt $1976: 160 \mathrm{~V}$ ).

Saamgevat: vanweë die vrede - deur Christus - kan die orde funksioneer - ook deur Christus. Die orde is nog onvolkome, maar reeds permanent; dit word deur die skrifbelofte gedra, naamlik dat dit eenmaal voltooi sal word wanneer elkeen en alles volkome op sy eie plek sal funksioneer, na sy eie aard, soos deur God bepaal (vgl. Pop 1978: 387).

Laat ons nou terugkeer na die aanvangsin in die kerkorde: "Om goede ordre in der Gemeente Christi te onderhouden, zijn daar in nodig..." Die kerkorde stel die skriftuurlike beginsel dat die orde onderhou moet word. (Let op die fyn nuansering: "onderhou", selfs nie eens "handhaaf" nie!). Wáárom die orde onderhou moet word, word deur die skrifbeginsel gestel (1 Kor 14:33, 40): vanweë die vrede met God (en die daaruitvolgende vrede met mekaar). Die orde is dus nie die hoogste doel van die kerk nie. Die vrede met God, die heil in Christus is! Daarom praat die kerkorde keurig-bepalend van "die goeie orde", natuurlik in onderskeid met 'n wetlike, juridiese orde. Hierin kom tot uiting dat die orde nie 'n "ordologie" is nie, nie 'n grootheid waaronder die kerk in diensbaarheid moet buig nie. Die orde is nie ' $n$ juridies-bepaalde eie-wetlikheid wat 'n dwinoelandy in die kerk ten gevolg het nie (vgl. Rutgers $1890: 39$, 41). Die kerklike orde is nie 'n sisteem nie en die kerkorde is nie die bron waaruit die kerkreg bedryf moet word nie. Nee die kerkorde is die skrifspieël waarin die kerk homself en sy handelinge voortdurend moet spieël ter onderhouding van die vrede met God (vgl. Trimp, 105 V.): sodat die kerk nie 'n mensgemaakte struktuur word nie; sodat die kerk se organisasie nie in botsing met sy wese kom nie; sodat die vertikale verhouding en die horisontale verhoudinge reg onderhou word: sodat die kerk se uiterlike gelaat in ooreenstemming met sy innerlike doel bly (vgl. Calvyn 1956: IV, X, 27). As sodanig is die kerkorde wél bindend, maar sy bindingskrag is gesetel in die vrede met God. Daarom praat die kerkorde van die onderhouding van "die goeie orde".

Ek stel: die kerkorde se relevansie lê in die vrede met God; die kerkorde se gesag lê in die Woord van God; die kerkorde se aansien lê in sy diens tot God.

\section{KERKORDE IN DIENS VAN ... DIE SKRIFORDE}

Nie die kerkorde nie, maar die lewende verkondiging van die Woord is die enigste konstituerende element van die kerk. Hierdie 
insig is een van die kruispunte waarop die weë van die protestantse kerke en die van die Roomse kerk skei. Reeds Luther het in sy stryd om 'n regverdige God te vind, onder die juk van die Roomse hiërargie, tot die insig gekom dat die kerk vir sy ontstaan en sy voortbestaan nie afhanklik is van die Corpus Iuris Canonici waarin die apostoliese suksessie en die leeronfeilbaarheid van die pous bepaal is nie (Mörsdorf 1964 : 27; Erler $1983: 28$ ). Soos niemand deur baie eeue voor hom nie, het Luther teruggegryp na die Woord van God. Waar die lewende Woord verkondig word, dáár kom die kerk tot stand (vgl. Wehrhahn $1956: 14$; Van 't Spijker 1983:117, 176; Hermann $1960: 342,367$ VV.; Exalto $1983: 186-188$ ). Hiermee het Luther en die ander reformatore egter nie ontken dat die opdrag tot kerklike orde en die beginsels vir die kerklike orde terdeë in die Heilige Skrif gegee is nie. Dit sou ook die algemeen geldende standpunt onder Gereformeerde teologië word (vgl. Sillevis Smitt 1910 : 114; Bronkhorst $1947: 276$; Van Itterzen 1974:52; Pont $1981: 9$; Nauta $1971: 16$ ). Hoewel die benaming 'kerkorde' nie in die Skrif voorkom nie, word die noodsaaklike prinsipiële reëlings in die kerkorde pertinent onder die aandag gebring: byvoorbeeld met betrekking tot die tug (Mt 18:17 V.V.); met betrekking tot die onderhoud van die dienaars (Mt 10:10; Gl 6:6; Flip 4:15; 2 Ts 3:9); met betrekking tot die vereistes wat aan die dienaars gestel word ( $1 \mathrm{Tm}$ $3 ; 5: 19)$ : en so voort. Die bepalinge en voorskrifte wat as die fundamentele lyne vir die kerklike organisasie geld, trek saam in die samevattende ordereëling wat in 1 Korintiërs $14: 40$ as opdrag aan die kerk gegee word: "Laat alles betaamlik en ordelik gebeur") vgl. ook Kol. 2:5). Die antwoord van die kerk op hierdie opdrag is die kerkorde waarin die beginsels en die bepalinge van die Skrif vir die kerkorganisasie en die kerkregering verwoord en gesistematiseer word (vgl. Spoelstra $1966: 11$ ).

Vir die daarstelling van ter sake reëlings vir die kerk as organisasie voer Calvyn juis op grond van 1 Korintiërs $14: 40$ 'n kragtige pleidooi, sodat "de kerken (niet) van hun senuwen beroofd worden en geheel misvormd en verstrooid worde" nie (Calvyn 1956: IV, X 27). Op die spoor van Calvyn is daar onder Gereformeerde kerk- reg skrvwers algemene instemming daarmee dat daar ook praktiese reëlings (generales regulas), wat nie noolwendig direk uit die Woord afgelei hoef te word nie, gerig op bepaalde plek- en tyds omstandighede (circumstantialia teenoor substantialia) in die kerkorde opgeneem moet word en wat die kerkorde derhalwe veranderbaar maak (Praamsma 1946:8; Hovius 1962:11, 25). Waar hierdie reëlings pertinent met die gees en strekking van die Heilige Skrif ooreenkom, is ook hierdie reëlings vir Calvyn in die skrifopdrag tot kerkorde gewortel en derhalwe "gelijk als uit den mond van Christus zelven" (Calvyn 1972 : 248; vgl. ibid 1956: IV, X, 30). Nogtans moet sulke praktiese reëlings van algemene aard in die kerkorde tot die noodsaaklike beperk word (ibid 1956 : IV, X 32). Ook die kerklike belydenis open die deur vir kerkordelike bepalinge wat nie noodwendig in die Skrif voorkom nie, maar wat met die strekking en die gees van die Skrif ooreenkom (N.G.B., art. 32). 
Hieruit blyk dat die kerkorde in essensie analoog met die direkte ordebepalinge sowel as die beginsels vir ordebepalinge in die Skrif moet wees, hoewel die kerkorde duidelik nie 'n sinoniem daarvan is nie. Ook Bucer handhaaf 'n duidelike onderskeid tussen die Gees-geïnspireerde orde (die skrifbeginsels) en die mens-gepositiveerde orde (die kerkorde). Laasgenoemde se gesag setel juis in sy fundering in eersgenoemde (vgl. Van't Spijker 1972:27, 28). Die kerkorde is mensewerk wat steeds appellabel aan die Skrif bly (vgl. Bouwman $1970: 326 \mathrm{~V}$.).

Om die noodsaaklike onderskeid tussen die prinsipiële skrifgegewens met betrekking tot die kerklike orde enersyds en die interpretasie en sistematisering daarvan in 'n kerkorde andersyds te handhaaf, wil ek gewoon van skriforde teenoor kerkorde praat. Indien die onderskeid tussen skriforde en kerkorde nie voluit gehandhaaf word nie, loop die kerk terug op sy spore na die Rooms katolisisme toe, waar 'kerkorde' as die sinoniem van 'skriforde' gesien word. Rooms gesproke is daar maar een 'kerkorde' en hierdie 'kerkorde' is absoluut, dit staan in die mistiek-organiese stroom van die waarheid wat as een magtige sintese van die geopenbaarde wil van God en die kerklike tradisie funksioneer. Hierdie 'kerkorde' is die Codex Iuris Canomici wat vanaf 1918 figureer nadat dit saamgestel is uit die Corpus Iuris Canonici waarvoor die basis al omstreeks in 1140 gelê is (Plomp 1978:143) Die Codex Iuris Canonici is ius divinum van waaruit die Roomse kerkreg (ius humanum) bepaal word (vgl. Mörsdorf $1964: 27$; Erler 1983 : 28. 125; Leitmaier $1971: 66 \mathrm{~V}$.). Volgens die siening van Rome het die Codex Iuris Cononici 'n selfstandige bestaansreg naas die Skrif, gelykstaande daarmee.

Vir 'n kerk wat hom slegs aan die Woord van God onderhorig hou, is sy kerkorde in die skriforde gewortel en tegelyk 'n weerspieëling daarvan. Dit hou in dat die kerkorde aan die een kant geen selfstandige bestaansreg los van die Heilige Skrif het waarin die 'goddelike' reg' gefikseer is soos in die Codex Iuris Canonici nie, en aan die ander kant mag die Bybel ook nie gehanteer word as 'n tydlose wetboek soos die genoemde Codex Iuris Canonici nie (vgl. Trimp 1982 : 108).

Die onderskeid tussen ius divinum en ius humanum is irrelevant vir 'n kerk wat slegs aan die Woord van God gehoorsaam wil wees. Beide Luther en Calvyn het geen behoefte gehad om in hierdie kategorië te dink nie. Hulle het die ampsbediening nie as 'n selfstandige grootheid teenoor die reg van God gestel nie; nee, die amp is vir hulle volkome ondergeskik aan die Woord (vgl. ibid : 105 -107) en word derhalwe daardeur bepaal en beheers. Hierdie siening beteken nie ' $n$ ontkenning daarvan dat daar met betrekking tot die kerkorde onderskeidend rekening gehou moet word met die goddelike bepalinge (die skriforde) en die menslike ordinansies wat die kerk in opdrag van die Skrif (1 Kor 14:40; N.G.B., art. 32) mag daarstel nie. Die direkte én afleibare goddelike bepalinge is onveranderbaar (Praamsma 1946:8). Maar die menslike ordinansies mót selfs na die eis van plek- en tydsomstandighede veranderbaar 
wees om in elke nuwe situasie nuut te soek na die orde, die vorm en die beeld van die kerk in opdrag van die Here. Noodsaaklike veranderinge aan die kerkorde is vir Voetius deel van die aedificatio ecclesiae. Voetius het nie 'n vir eens en altyd afgeslote kerkordekonsep gehuldig nie (Plomp $1978: 146$ ). Die menslike ordinansies, oftewel die regulatiewe bepalinge in die kerkorde, is egter nie op 'n afsonderlike amps- of kerkgesag gegrond nie, maar moet gesien word in volkome afhanklikheid van die skriforde. Ook in hierdie bepalings wat vanuit die skrifopdrag op plek- en tydsomstandighede gerig is, moet in elke onderdeel die gloeiende kern van die heil van die Here gevoel en besef word (Van Ruler 1972 : 125). Die kerkorde bly derhalwe geheel en al diensbaar aan die Heilige Skrif, wat die diepste grond vir sy bindingskrag is.

\section{DIE KERKORDE IN DIENS VAN ... EEN ORDEGEWER}

Nou het dit ook reeds duidelik geword, naamlik dat die kerkorde nie net 'n prakties-tegniese reëling is waarvolgens op die eenvoudigste wyse die doeltreffendste regeringsmetode vir die kerk daargestel word nie. Met ander woorde, die kerkorde is nie 'n puur aardse en wêreldse steierwerk rondom die puur geestelike bouwerk van die kerk waardeur laasgenoemde opgebou moet word nie. Nee, die kerkorde kom uit die wese van die kerk op. En die wese van die kerk is Jesus Christus. Dit is Christus wat aan die kerk deur sy Gees (nooit los van die Woord nie) die vryheid en die wysheid gee om deur die daarstelling van ordereëlings diensbaar te wees aan die beveiliging en die onderhouding van die Woordverkondiging wat die septer van Christus is (Trimp $1982: 107$ ).

As Ordegewer is Christus die organiese Hoof. maar ook die volstrekte Gesagshoof van sy liggaam (1 Kor $11: 3$; Kol. 2:10). As Ordegewer en Gesagshoof is Hy lewens-één met sy kerk, nie meganies nie, maar op organiese wyse (vgl. Van der Walt 1976:45, 47). Dat die kerk lewenséén met Hom as Ordegewer en Regeerder is, beteken dat die kerk nie net aan Hom behoort nie, maar dat die kerk hoegenaamd nie selfstandig sonder Hom kan bestaan nie. Hy is die oorsprong. do 4 en groei van die kerk (Ef $4: 15$; Kol $2: 12-19 ; 3: 1$ ). Derhalwe kan die kerk nie kerk wees sonder die orde wat $\mathrm{Hy}$ vir sy kerk bestem het nie (vgl. Du Plooy 1982:19V). Die kerk se gehoorsaamheid aan die orde in diens van die Ordegewer is dus van primêre belang.

Die vraag wat ek hier wil stel, is of daar slegs een kerkorde kan wees en of daar meer kerkordes onder die beskikking van die een Opdraggewer moontlik is.

Om die vraag te beantwoord moet 'n mens 'n skriftuurlike perspektief op die kerk hê. Waar God se Woord en Gees werk, kom die kerk met sy nuwe orde tot stand (vgl. Milner 1970:40). Derhalwe is die orde van die kerk wesenlik anders as die orde van enige gewone samelewingsverband, instituut of struktuur (vgl. Spoelstra 1978:22). Ander wetmatigheid en ander reëls geld vir die bestaan van die kerk as wat vir 'n menslike vereniging of -instituut geld. As daar nle 
vanuit die mens nie, maar vanuit die Skrif oor die kerk nagedink word, moet die kerk as 'n produk van die herskepping gesien word (vgl. Kuyper $1909: 227$ ) en dan moet die kerk verstaan word vanuit "die orde en de gestalte der regeringsinrichting, die Hij zelf heeft voorgeschreven" (Calvyn $1956:$ IV, VI, 9). Hierdie wesenlik ander "orde en gestalte van regeringsinrigting", wat Christus self voorgeskryf het, is die skriforde.

Daar is slegs één Hoof, één liggaam en één orde vir daardie liggaam. Hierdie een skriforde is die eksplisiete en direk afleibare beginsels wat Christus en sy apostels in die Skrif gegee het met betrekking tot die dienste, die kerklike samekomste, die kerklike leer en die kerklike toesig daaroor, die sakramente, seremonies en die kerklike tug. Daarom stel Calvyn ter inleiding van sy betoog hieroor: "Nu moeten wij spreken over de orde, door welke de Here wil, dat zijn kerk bestuurd wordt" (1956: IV, III, 1). God self het eén orde vir sy kerk vasgestel en wil erken word as synde teenwoordig in hierdie orde (Kuyper $1898: 5$ ).

Omdat die Skrif egter nie 'n wetboek is waaruit elke individuele reël vir die kerk in duidelik geformuleerde definisies afgelees kan word nie, maar die grond is waaruit die beginsels van die kerkorde met behulp van die kerkreg opgediep moet word, kan daar in die praktyk verskillende formuleringe van die kerkorde wees. Sodra 'n mens die toepassing van die skriforde in die kerkorde deur "afleiding" en "nadere reëling" vanweë plek en tydsomstandighede erken (Van der Linde $1965: 31$ ), gee jy toe dat daar gedifferensieerde formuleringe van die een skriforde kan wees. Kerkordes mag dus in differensiëring van mekaar verskil, maar nie in kontrastering nie. Kerkordes wat wel konstrasterend van mekaar verskil, bring nie daarmee die perspecuittas van die Heilige Skrif in die geding nie, maar bring die versondigde interpretasievermoë en die eiewilligheid van die mens tot uiting.

Vanweë die verskille in plek-, tyd- en kulturele omstandighede kan en moet die één Ordegewer deur onderskeie (nie verskillende nie) kerkordes gedoen word. Want in die kerkorde gaan dit om die heerskappy van Christus self in sy kerk, toegespits op konkrete omstandigheidsaspekte.

\section{DERHALWE: DIE KERKORDE IN 'N SEKONDERE FUNKSIE}

Voordat ek by die praktiese hantering van die kerkorde kom, verwoord ek eers enkele konklusies:

Dit is nie waar dat die Bybel toeslaan waar die kerkorde geopen word nie... mits die Bybel éérs geopen word en dan die kerkorde. Die kerkorde is geen Codex Iuris Canonici nie. Die kerkorde is afhanklik van die Skrif. Trouens, die kerkorde wil vir die doel van die kerkorganisasie en die kerkregering niks anders wees as die kerklike weg na die Heilige Skrif toe nie.

Die kerkorde skep nie die ampte nie, maar gee dit weer. Die kerkorde konstitueer nie die kerklike vergaderinge nie, maar gee ordelike beslag daaraan. Die kerkorde stel nie die Woordverkondiging 
en die sakramentsbediening daar nie, maar beveilig en handhaaf dit. Die kerkorde beveel nie die kerklike tug nie, maar sistematiseer dié skrifopdrag tot kerklike prosedure. Die kerkorde skep nie die kerklike instituut nie, maar gee 'n spieëlbeeld daarvan.

Die kerkorde stel die kerklike instituut voor sy skriftuurlike infrastruktuur ter wille van sy gehoorsaamheid, ordelikheid, doeltreffendheid, kontinuïteit en regsekerheid (vgl. Trimp 1982:206). Maar die kerkorde stel ook die kerk voor die waarheid van sy bestaan en sy roeping tot kerk-wees in die wêreld. Die kerkorde herinner die kerk daaraan dat hy die draer en die beskermer van die waarheid is (1 Tim $3: 15$ ), en hy beveilig 'n kerklike ruimte vir die kerk waarbinne die kerk die geskermer en draer van die waarheid op 'n kerklike wyse in die wêreld kan wees.

Die kerkorde stel die kerk voor die eis dat hy in die vryheid van die waarheid sal leef en nie in die benepenheid van 'n eie-wetlikheid nie (As die waarheid byvoorbeeld in 'n kerk verlore geraak het, en daar is nog ouderlinge, help dit niks. Want die ouderlinge setel immers in die waarheid en moet die waarheid bedien). Die kerkorde staan in diens van die geestelike wasdom van die kerk: dit is die beveiling en bekragtiging van die oikodomé (opbou) van die liggaam van Christus.

Daarom moenie van die kerkorde 'n afsonderlike stel reëls gemaak word, los van die Heilige Skrif nie. Die kerkorde is die kerk se persoonlike visie op sy eie gelaat uit die Heilige Skrif. Die kerkorde stel ons voor ons historiese afgrensing van die wêreld, maar dit stel ons $66 \mathrm{k}$ voor ons eskatologiese oorwinning oor die wêreld.

Waar die kerkorde se lewensnoodsaaklike basis die Heilige Skrif is, is die belydenis, die kerkreg en die kerkordelike historie die onmisbare konteks waarbinne die kerkorde funksioneer. Kom ons stel dit so: die kerkorde word deur die Heilige Skrif gefundeer; die kerkorde word deur die belydenis genormeer; die kerkorde word deur die kerkreg geprogrammeer; die kerkorde word deur sy geskiedenis gesitueer. Buite-om die konteks word die kerkorde 'n reglementebundel en die hantering daarvan beoefening van puur positiewe reg.

Ek stel dié perspektief: die eie glorie van die kerkorde is sy sekondêre funksie. Buite-om sy dienskneggestalte hou sy bestaansreg op. Maar in sy dienskneggewaad het hy 'n noodsaaklike plek...' n plek voor die aangesig van die Koning. 